\title{
Underground mining slurry transportation viability
}

\author{
Binay Samanta $^{1}$ (D) Arun Baran Samaddar ${ }^{1,2}$
}

Received: 5 September 2018/Revised: 15 April 2019/Accepted: 30 May 2019/Published online: 5 July 2019

(C) The Author(s) 2019

\begin{abstract}
Underground mining requires lot of water pumping to surface which increases cost. Because of safety, support, ventilation and environment costs underground mines are closing down gradually all over the world. This innovative paper is based on method studies by computer programming with realistic data. With development of electronic control systems, coal water slurry mix can be remote controlled for transport to surface Separator-bunker. Main consumers need powdered coal/mineral like thermal power stations, for feeding to Fuel Burners of boilers, generating power or in steel plants for feeding into coke ovens to make hard coke for charging into Blast Furnaces for making pig iron. Feed for coal washeries also require crushed coal and output of washed coal as slurry can be sent to coke ovens of steel plants directly. Production from mine faces should be taken through lump-breaker and conveyed to a mixing chamber, near panel sump, from where adequate capacity slurry pump will propel up to pit-top. The projected financial benefit can be several millions of Rupees per year, as compared to road, rail conveyor or winders is shown, by run of a computer program in Java, with realistic cost figures from mines.
\end{abstract}

Keywords Electronic control · Slurry pumping · Continuous miner · Lump-breaker · Panel sump · Mixing chamber

\section{Introduction}

The study was needed to make underground mining viable as India is endowed with plenty of reserves of coal and minerals, which are the raw materials for the products of the industry. Specifications and objectives are included in the discussion section. About 308.802 billion tonnes of coal

A. B. Samaddar is former professor, as retired.

Electronic supplementary material The online version of this article (https://doi.org/10.1007/s40789-019-0257-2) contains supplementary material, which is available to authorized users.

Binay Samanta

iitism.bks@outlook.com

Arun Baran Samaddar

absamaddar@gmail.com

1 IIT (ISM), Dhanbad, India

2 NIT, Ravangla, India reserve have been estimated by GSI as on 1st April, 2016. The operating cost of mechanized opencast mines has escalated also with increase in prices of essential inputs, spiraling wages and improved welfare facilities to employees. Gradual introduction of coalface loading with SDL/LHD is continuing for decades now and yet there is marginal improvement of coal productivity from underground mines and most of them are losing. But remaining reserves are deeper and improvement in underground production and profitability is essential for sustainable development. Slurry pipelines carry usually about 50 percent coal and 50 percent water by weight. Pulverized coal is mixed with water in a mixing tank, which contains one or more large rotating wheels or propellers that keep the particles uniformly mixed. Next, the slurry enters the pipeline as suction to pumps for forcing the slurry over long distances. 


\section{Literature survey}

Briefly literature survey revealed the following main points. The use of water for the transport of coal underground is recorded as far back as 1927. It became the method of choice for small private operations on the West Coast of the South Island, New Zealand, as it required very little capital investment and allowed small, steeply dipping blocks of coal to be mined competitively with the larger State owned conventional operations.

The United States pioneered the coal-slurry pipeline technology and the first long-distance coal-slurry pipeline was constructed in Ohio in 1957. The earlier long coalslurry pipeline is the Black Mesa pipeline in the United States, built in 1970; 18-inch pipeline transports 4.8 million tons of coal per year from Black Mesa, Ariz., to southern Nevada, over a distance of 273 miles very successfully. The World's longest slurry pipeline is at Etsi, USA $1036 \mathrm{~km}$ long, $38^{\prime \prime} \mathrm{dia}$, and $25 \mathrm{Mt} / \mathrm{yr}$ capacities carrying coal slurry and started in 1979. One of the most successful slurry pipelines being used in India is at Kudremukh from where iron ore slurry is being trans $\neg$ ported through a stainless steel pipeline $57 \mathrm{~km}$ long, $430 \mathrm{~mm} \Phi$ by 5 slurry pumps rubber lined, centrifugal type in series, each of 385 $\mathrm{kw}$ approximately. The longest iron concrete slurry pipeline of the world is at Samarco, Brazil, $253 \mathrm{~km}$ long, 20" dia, $12 \mathrm{Mt} / \mathrm{yr}$ capacity commissioned in 1977.

\section{Cost parameters}

There are many types of costs. Key terms are Fixed costs; Variable costs; Total costs etc. Total costs = fixed costs + variable costs. $=\mathrm{a}+\mathrm{bQ}$; Average costs: The total cost divided by the level of output. Marginal (or incremental) cost: The derivative (difference) of Total Cost with respect to a change in output. Marginal Cost MC; Incremental Cost IC; Opportunity costs: The actual opportunities forgone as a consequence of doing one thing as opposed to another. Opportunity cost represents true economics costs, and thus, must be used in all cases. Social cost: The cost the society incurs when its resources are used to produce a given commodity, taking into account the external costs and benefits. Private cost: The cost a producer incurs in getting the resources used in production.

\section{Materials and methods}

For the program design, realistic costs of slurry pumps, in place of haulage, conveyor, winding approximate costs have been taken. Even in opencast mine, water has to be pumped out of the mine in any case; only more horse power is needed for moving the coal particles. Underground haulage and winding capacity can be more effectively utilized for material supply, like supports, bricks for ventilation or isolation stoppings etc. if hydraulic transport is adopted. In old coalmines, for want of sufficient winding capacities, high production continuous miner or Power Support Longwall cannot be operated for viability. In order to make a realistic estimate of cost-benefit of slurry pumping transport vis-à-vis winding and transport in mines, a study of successful existing pipelines are made. Electronic control can be installed exemplified with Program Logic Controller (PLC) in Fig. 1.

As underground mines are usually deeper, compared to quarries or opencast mines, water inflow is quite high. Pumping of water from coal faces to district sumps and then to main underground sump at pit-bottom, from where discharge to surface drainage is done. Amount of water to be pumped depends on many factors of local geology. Models predicting ground water inflow rates could be computed from various equations depending on the discharge rate and transmissivity seepage or flow-back or drawdown connected to rate of pumping etc. Discharge rate is found from local velocity, effective area, aquifer thickness, and width of depillaring place.

\subsection{Underground mine}

Planning additional production of 1 Mty from an underground mine, for instance by a Continuous Miner. Model EIMCO 2810 with shuttle car, trailing cables, Feeder Breaker, Scoops with battery charger, communication, electrical parts, switchgears, transwitch, Roof-bolter would require about Rs. 400 million. Annual Depreciation and Interest @ 25\% x Rs. $40=$ Rs. 10 Cr. or 100 million and so investment would be Rs 100/t. Manpower by training of existing operators and mechanics has been considered. With the experience as part-time researcher and working as General Manager in the largest coal company of India, Coal India Ltd (CIL), major factors have been taken into account for computing costs from price list and cost sheets a few years back in coding the computer program in Java.

Additional investment for hydraulic transport

A. Slurry pump-Heavy Duty (McNally) (VASA HD) with FLP motor and GEB-Capacity-250 lps or 15 $\mathrm{m} 3 / \mathrm{min}$ or $900 \mathrm{~m} 3 / \mathrm{hr}, 300 \mathrm{tph}$ of coal for head$180 \mathrm{~m}=\$ 0.265$ million

B. Crusher-(Roll -Sayaji) Type FLP, 300 tph, $80 \mathrm{~kW}$ complete with GEB $=\$ 0.176$ million

C. Mixer Chamber-controlling coal: water ratio $=\$$ 0.068 million 


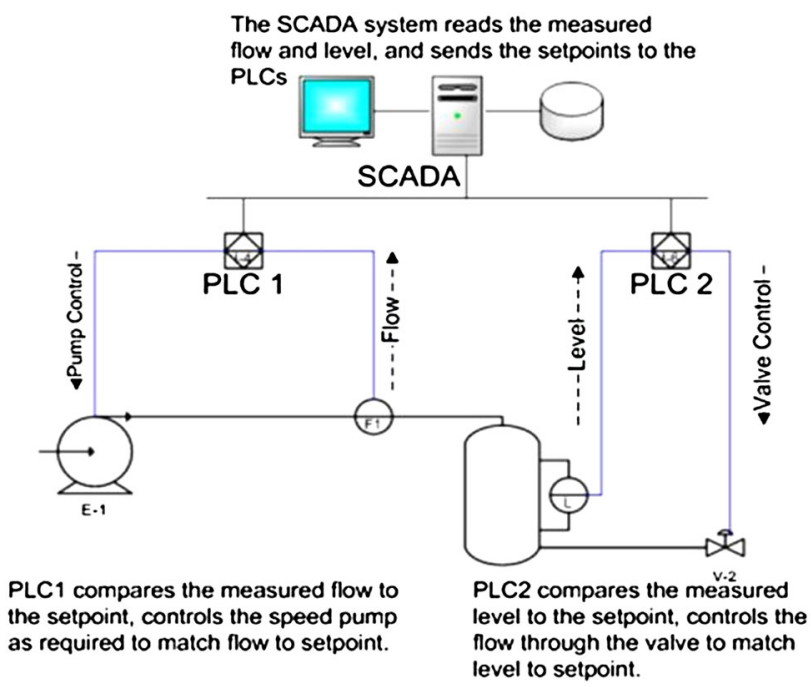

Fig. 1 Electronic control system recommended

D. Miscellaneous (PVC pipe-coal slurry not abrasive or corrosive as sand) - $200 \mathrm{~mm}$ (D, $500 \mathrm{~m}$ (EMCO Make) $=\$ 0.102$ million

Total—coal 300 tph or @ 50\% utilization 3600 tpd for 300 days/yr producing

1 Mt of coal/yr (designed capacity of Continuous Miner $)=\$ 10.7$ million

Annual Depreciation and Interest @ 25\% × \$10.7 million $=\$ 2.7$ million

Thus, we find approximately only $\$ 27 / \mathrm{t}$ of investment is required. No additional investment for haulage and transport would be needed.

\subsection{Cost-benefit computation}

A computer program was coded in java and run in which: trdn- transport distance necessary in $\mathrm{km}$ taken in steps of $0.5 \mathrm{~km}$; thfd- total head for delivery including friction head @ 10\% of pipe length in $\mathrm{m}$; cugcw- cost of underground conveyance and winding in \$ million per year; stct- surface transport cost by truck in $\$$ million per year; ssbc- standard separator-bunker cost of $\$ 0.6$ million; tcht- total cost of hydraulic transportation in $\$$ million per year; cbht-costbenefit of hydraulic transport in $\$$ million per year. It is assumed that $22 \%$ of the annual depreciation + interest and 300 is approximate number of working days in a year. The costs of pumps and pipelines have been taken from CMPDIL and of Separator-bunkers from ECL tender and other figures have been based on experience.

Figure 2 shows a heavy duty modern slurry pump suitable for underground application.

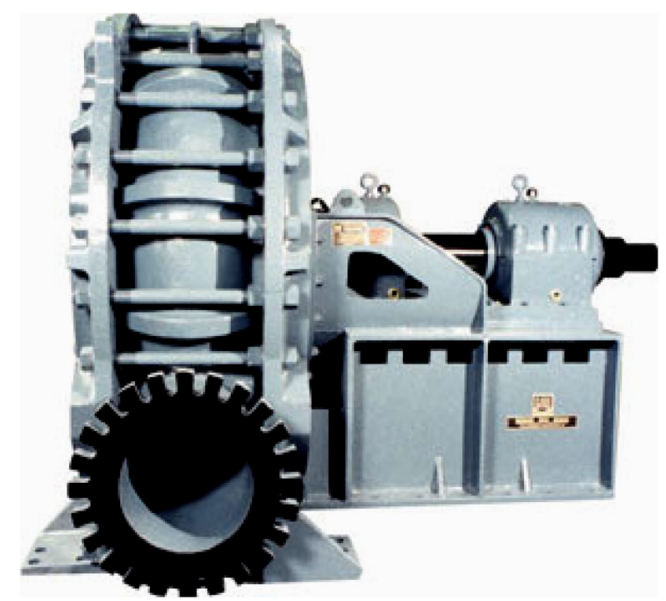

Fig. 2 Heavy duty slurry pump-TBC

\section{Results}

Therefore, we find that the cheapest conventional method of conveyance would be 28.6 million costlier per year than hydraulic transport. Moreover, approximate time for sinking, lining fitting and winding $150 \mathrm{~m}$ shaft would require at least 3 years and for $450 \mathrm{~m}$ tunneling 2 years, while the hydraulic system could be implemented in few months.

Figure 3 displays flowchart of hydraulic transport costbenefit.

Layout can be similar to that adopted for hydraulic mining, used for breaking down soft coal and sluicing it down by high pressure water jets, applied through monitors. Although, hydraulic mining of coal has been deployed experimentally within the United States and Canada, even in India in Assam and at Amlabad Colliery did not succeed, because of hard coal. But, it is practiced extensively in the Kuznetsk Basin of Siberia for steeply pitching deposits, with thick coal seams containing soft coal or friable bands, and found productive, safe, and economical. Here the water is also used to transport the coal from the working faces to a common point through open channels and from the common point to the surface through high-pressure hydraulic transportation systems (Fig. 4).

\subsection{Resulting benefits}

(1) Saving in haulage and winding costs could be more than $30 \%$ of average $\$ 12 / \mathrm{t}$

(2) Saving in dust control expenditure would be $80 \%$ of $5 / \mathrm{t}$ to $4 / \mathrm{t}$

(3) Creating extra coal transport capacity, of 1 Mty without shaft sinking.

Total cost-benefit per tonne may be $\$(16-2.7)=\$ 13.3$ or saving per year $=\$ 13.3$ million. 


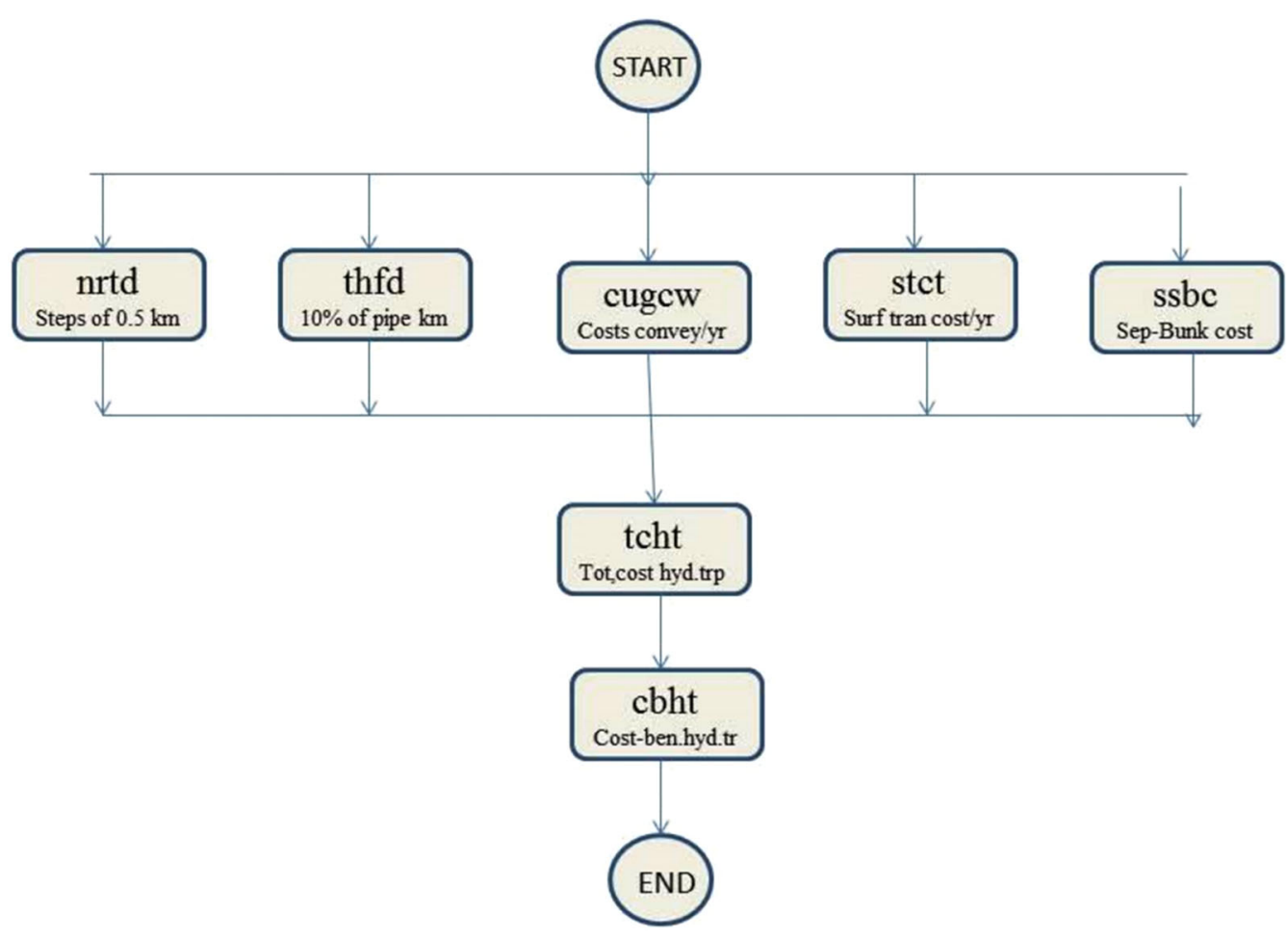

Fig. 3 Flowchart-hydraulic transport cost-benefit

SUMMARY OF PROGRAM OUTPUT

\begin{tabular}{|c|c|c|c|c|c|}
\hline DISTANCE & HEAD & CSTUG & COSTSURF & TCSTHYDT & CSBFHYDT \\
\hline 5.0 & 100 & 192.5 & 152.5 & 62.6 & 282.3 \\
\hline 5.0 & 120 & 200.5 & 156.5 & 66.6 & 290.3 \\
\hline 5,0 & 140 & 208.5 & 160.5 & 70.6 & 298.3 \\
\hline 5.0 & 160 & 216.5 & 164.5 & 74.6 & 306.3 \\
\hline
\end{tabular}

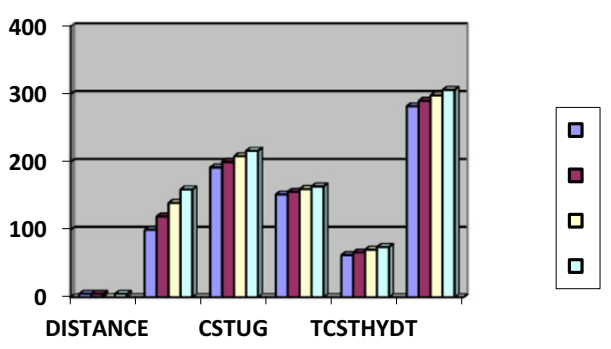

Fig. 4 Graphical representation of cost-benefit

\subsection{Additional investment considered}

A. Shaft sinking with lining $6 \mathrm{~m} \Phi, 150 \mathrm{~m} @ \$ 0.35$ million per $\mathrm{m}=\$ 52.5$ million

B. Winder, Headgear, Cages, Guide ropes, shaft fittings, winding ropes $=\$ 30.0$ million $A^{\prime}$ Incline drifting with lining and support-450 m @ \$40,000/m=\$18.0 millionB' Incline Conveyor 450 m, 1000 mm wide, @ $\$ 20,000 / \mathrm{m}$ alignment,Grading of structure, drive, belting, and motor with GEB $=\$ 9.0$ millionConsidering the cheaper alternative of incline and conveyor $(18+9)=\$ 27.0$ million

C. Underground Conveyor structure, drive, belting, $350 \mathrm{~m}$ and motor with GEB $=\$ 7.0$ millionTotal for incline option for 1 Mty of coal $=\$ 61.0$ millionAnnual Depreciation \& Interest @ 25\% × \$61 or cost per year $=\$ 15.3$ million 


\section{Discussions}

Hydraulic mining with very soft coal reserve, extraction with high pressure jet monitor has been and tried and found successful in some cases. But, here we are examining extraction by Longwall Shearer or Continuous Miner, transportation by hydraulic pumps. Auto-oxidation of coal depends upon ignition temperature and crossing point temperature, but is aggravated by buried broken coal, in surface or underground, when heat generated through trapped air, cannot be dissipated by ventilating air. Slurry transportation minimizes such risks and for achieving break-even level of production in Indian coalmines, continuous mining systems have to be increased and R\&D in hydraulic transport underground can be prospective.

The World's longest slurry pipeline is at Etsi, USA $1036 \mathrm{~km}$ long, $38^{\prime \prime} \varphi$, and $25 \mathrm{Mt} / \mathrm{yr}$ capacities carrying coal slurry and started in 1979. The longest iron concrete slurry pipeline of the world is at Samarco, Brazil, $253 \mathrm{~km}$ long, $20^{\prime \prime} \varphi, 12 \mathrm{Mt} / \mathrm{yr}$ capacities, commissioned in 1977. The operating experience of long distance slurry pipelines at Savage River, Tasmania, Australia, Pena Colorado, Colima, Mexico, Samarco, Brazil and many others were economical. There are slurry pipelines for coal, copper conc. limestone, phosphate, tailings, gelsunite etc. Most of the slurry pipelines utilize positive displacement piston or plunger type pumps. These pipelines show pronounced savings, compared to conventional systems of trans $\neg$ port.

One of the most successful slurry pipelines being used in India is at Kudremukh through a stainless steel pipeline $57 \mathrm{~km}$ long, $430 \mathrm{~mm} \varphi$ by 5 slurry pumps rubber lined, centrifugal type in series, each of $385 \mathrm{~kW}$ approximately. Slurry pipeline transport of coal carry special promise as in India, rail and road traffic is getting saturated. Diesel trucks have been studied to create maximum air pollution, for example CNG conversion in Delhi. Major consumers of coal like Steel Plants and Thermal Power Plants require powdered coal for supply to coke ovens and pulverized fuel burn $\neg$ ers. So, linked pipelines from the mines to washeries, coke ovens or power stations can help in attaining the target of coal production with saving in transportation costs.

Hitachi Company of Japan had developed Hydro-hoists and successfully used in 3 collieries in Japan, in transporting coal from faces directly to washery on the surface. The main devices in the hydro-hoists are feed pipes, operating valves-plate type, bladeless pump and highpressure water pumps. Valves operate in 3 cycles; coalwater slurry is sucked up and sent to feed pipe, next when the feed pipes are full bladeless pump pushes till pipes are full and finally the high pressure pump pushes to surface delivery point.
In case of hydraulic transport separator bunkers have to be made. Water drained from there can be taken through pressure filter or other methods of filtration for industrial or domestic use. Slurry pumps of small capacities are used in coal face pumping. Long distance ranges of slurry pumps have: discharge diameters: $12^{\prime \prime}$ to $44^{\prime \prime}$; Flows: 5000 to 140000 GPM; TDH to $300^{\prime}+/$ stage; and Capabilities beyond 12000 HP. Control device sends the commands to valves, and protection devices. Hydro-hoists installed are summarised in Table 1.

Abrasion and corrosion resistant slurry pumps can deal with any type of material and performance with coal would be definitely better than sand or any other material. Relatively smaller designs of slurry pumps are MEGA, WBC, PGD, LCC, LCV, LSA, LSR etc. Many other manufacturers of high capacity of slurry pumps are available like Metso, Krebs, Lawrence, Warman etc.

\subsection{Program run}

Table 2, shows exemplary run of program htcb.java showing cost-benefit of hydraulic transport as compared to conventional types for both surface and underground. The program flowchart and algorithm is shown in e-components. The main inputs are-CSTUGCON\&WIND: Cost of ug conveyance and windingl COSTSURFTRAN: Cost of surface transportl TCSTHYDTRANS: Total cost of hydraulic transportl CSBFHYDTRANS: cost-benefit by hydraulic transportation all in \$ Million per year.

Algorithm and flowchart help not only listing of the source program, but also in debugging of the program. Based on such realistic estimates, the program htcb.java has been coded for different distances and capacities for both underground and opencast mines to show cost-benefit projections. The source lines are coded in usually notepad program and compiled by C:ljdk1.3lbin with command javac htcb.java and when all errors are eliminated, htcb.class file is created. Java was chosen as the program can be compiled and run on all Operating Systems like DOS, WINDOWS, NT, MAC, LINUX etc. and so multi-platform use is possible. A program written in Java will not leak memory; because an application called the Java Virtual Machine (JVM) automatically handles memory management.

However, now high head slurry pumps are available to lift coal through pipelines to the surface, in place of hydraulic hoists used in Japan and elsewhere. Mine of the future would necessitate more advanced technology and management and many mines are getting larger and very specialized.

Mine mechanization with machine safety and system safety is required right from planning, project implementation and production stage. Geological problems in the 
Table 1 Hydro-hoist data used in Japan

\begin{tabular}{llll}
\hline Specifications & Furukawa-Yoshima & Chuko-Fukushima & Mitsui-Sunagawa \\
\hline Length of pipeline (m) & 1470 & 1000 & $2360 \mathrm{~m}$ \\
Actual lift (m) & 259 & 10 & 2250 \\
Type of solid & Coal pieces & Shaly coal & Coal pieces \\
Solid Sp. Gravity & 1.68 & 2.0 & 1.54 \\
Pipe Diameter (cm) & 16.5 & - & 16.5 \\
Max. Piece size (cm) & 5.8 & 5.0 & 5.0. \\
Mean velocity (m/s) & 3.8 & 3.6 & 3.5 \\
Quantity (m $3 / \mathrm{min})$ & 4.8 & 2.9 & 4.5 \\
Capacity (t/h) & 100 & 107 & 100 \\
Volume coal $(\%)$ & 20 & 30 & 25 \\
HP water pump & $5.3 \mathrm{cu} . \mathrm{m} / \mathrm{m} \times 530 \mathrm{~m} \times 750 \mathrm{kw}$ & $2.9 \mathrm{cu} . \mathrm{m} / \mathrm{m} \times 192 \mathrm{~m} \times 150 \mathrm{kw}$ & $5 \mathrm{cu} . \mathrm{m} / \mathrm{m} \times 850 \mathrm{~m} \times 1100 \mathrm{kw}$ \\
Bladeless pump & $4.8 \mathrm{cu} \cdot \mathrm{m} / \mathrm{m} \times 25 \mathrm{~m} \times 55 \mathrm{kw}$ & $2.9 \mathrm{cu} \cdot \mathrm{m} / \mathrm{m} \times 15 \mathrm{~m} \times 19 \mathrm{kw}$ & $3.1 \mathrm{cu} \cdot \mathrm{m} / \mathrm{m} \times 30 \mathrm{~m} \times 45 \mathrm{kw}$ \\
\hline
\end{tabular}

application of mechanized Long-wall mining in India are mainly due to hard roof and faults. Multi-Criteria Decision Making (MCDM) solves problems interactively by man machine phase. The bounds are of interest as successive trial decisions are generated. Dispersed collaboration in multi-firm, multi-team, product development project and slurry transportation has great future in mining industry for innate advantages.

\section{Conclusions}

Heavy duty slurry pumps are now available of various capacities and lifts and able to handle solids ranging from 60 to $228 \mathrm{~mm}$ and specific gravity of up to 1.8 . Conveyor carrying crushed coal output from Continuous Miner should feed into a mixing chamber, where mine water from underground pump makes slurry and serve as suction for Slurry Pump underground to surface.

Fast debugging could be done by applying special software named Net beans for java programs. The bugs if any can thereby get exposed for modification of the source program for smooth run and correct output results. Actual data sets entered for current year and then realistic projection has been taken for escalation @ 5\% per year for the next 5 years.

Main work on this research was done when the author was posted as General Manager, ECL, a subsidiary of Coal India, where many underground mines were being closed down. The program run has been done with lot of approximations; from Indian field data available. The purpose is to project as realistically as possible, the financial benefit possible with hydraulic transport, compared to the conventional ones. With production capacity assumed at 1 million tonnes and the program output in millions of Rupees, the results of the run virtually amount to $\$ /$ tonne. In some other cases, coal water slurry usually contains $65 \%$ coal, $34 \%$ water and $1 \%$ additive.

On analysis of results, from 0.5 to $5 \mathrm{~km}$ distance and $100-160 \mathrm{~m}$ head, it is found that CSTUGCON\&WIND or cost of underground conveyance and winding steeply increases from 55.2 to $216.5 \$$ per tonne. For the same range, COSTSURFTRAN or cost of surface transport increase less steeply from 33.2 to $164.5 \$ / t$. While for the same range, TCSTHYDTRANS or total cost of hydraulic transport, including separator-bunker is much less and increases flatly from 24.4 to $74.6 \$ /$. Naturally, it is found that CSBFHYDTRANS or cost-benefit of hydraulic transport for the same range is very steeply increasing from 64.1 to $306.3 \$ / \mathrm{t}$.

It is suggested that an S\&T project is taken up with Ministry of Coal, Govt. of India for setting up standards on implementation. Moreover, safety norms of electronic control of slurry pumping can also be established. All the same, for various other reasons, hydraulic slurry transport would be very advantageous for underground mining as enumerated below:

(1) Pumping of water has to be done in any case and so mixing coal/mineral particles and sending up by slurry pumps is natural justification for adopting the method, to the extent water is available in the mine.

(2) Air pollution is most often beyond permissible limit of Suspended Particulate Matter (SPM) $-200 \mu \mathrm{gm} /$ $\mathrm{m}^{3}$ and Respirable SPM limit of $70 \mu \mathrm{gm} / \mathrm{m}^{3}$ near mine transport sites, while hydraulic transport would be almost air-pollution free.

(3) Production capacity of most of the underground mines are limited to winding capacity and so additional production by face mechanization can be 
Table 2 Java program run: cost-benefit of hydraulic transport. Transport distance in kilometers and all costs in Rs million

\begin{tabular}{|c|c|c|c|c|c|}
\hline $\begin{array}{l}\text { Distance } \\
\operatorname{trdn}(\mathrm{km})\end{array}$ & $\begin{array}{l}\text { Head } \\
\text { thfd }(m)\end{array}$ & $\begin{array}{l}\text { CSTUGCON\&WIND } \\
\text { cugcw(Rs/mpy) }\end{array}$ & $\begin{array}{l}\text { COSTSURFTRAN } \\
\text { stct(Rs/mpy) }\end{array}$ & $\begin{array}{l}\text { TCSTHYDTRANS } \\
\text { tcht(Rs/mpy) }\end{array}$ & $\begin{array}{l}\text { CSBFHYDTRANS } \\
\text { cbht(Rs/mpy) }\end{array}$ \\
\hline 0.5 & 100 & 55.2 & 33.2 & 24.4 & 64.1 \\
\hline 0.5 & 120 & 63.2 & 37.2 & 28.4 & 72.1 \\
\hline 0.5 & 140 & 71.2 & 41.2 & 32.4 & 80.1 \\
\hline 0.5 & 160 & 79.3 & 45.3 & 36.4 & 88.1 \\
\hline 1.0 & 100 & 70.5 & 46.5 & 28.6 & 88.3 \\
\hline 1.0 & 120 & 78.5 & 50.5 & 32.6 & 96.3 \\
\hline 1.0 & 140 & 86.5 & 54.5 & 36.6 & 104.3 \\
\hline 1.0 & 160 & 94.5 & 58.5 & 40.6 & 112.3 \\
\hline 1.5 & 100 & 85.7 & 59.7 & 32.9 & 112.6 \\
\hline 1.5 & 120 & 93.7 & 63.7 & 36.9 & 120.6 \\
\hline 1.5 & 140 & 101.7 & 67.7 & 40.9 & 128.6 \\
\hline 1.5 & 160 & 109.7 & 71.7 & 44.9 & 136.6 \\
\hline 2.0 & 100 & 101.0 & 73.0 & 37.1 & 136.8 \\
\hline 2.0 & 120 & 109.0 & 77.0 & 41.1 & 144.8 \\
\hline 2.0 & 140 & 117.0 & 81.0 & 45.1 & 152.8 \\
\hline 2.0 & 160 & 125.0 & 85.0 & 49.1 & 160.8 \\
\hline 2.5 & 100 & 116.2 & 86.2 & 41.4 & 161.1 \\
\hline 2.5 & 120 & 124.2 & 90.2 & 45.4 & 169.1 \\
\hline 2.5 & 140 & 132.2 & 94.2 & 49.4 & 177.1 \\
\hline 2.5 & 160 & 140.2 & 98.2 & 53.4 & 185.1 \\
\hline 3.0 & 100 & 131.5 & 99.5 & 45.6 & 185.3 \\
\hline 3.0 & 120 & 139.5 & 103.5 & 49.6 & 193.3 \\
\hline 3.0 & 140 & 147.5 & 107.5 & 53.6 & 201.3 \\
\hline 3.0 & 160 & 155.5 & 111.5 & 57.6 & 209.3 \\
\hline 3.5 & 100 & 146.7 & 112.7 & 49.9 & 209.6 \\
\hline 3.5 & 120 & 154.7 & 116.7 & 53.9 & 217.6 \\
\hline 3.5 & 140 & 162.7 & 120.7 & 57.9 & 225.6 \\
\hline 3.5 & 160 & 170.7 & 124.7 & 61.9 & 233.6 \\
\hline 4.0 & 100 & 162.0 & 126.0 & 54.1 & 233.8 \\
\hline 4.0 & 120 & 170.0 & 130.0 & 58.1 & 241.8 \\
\hline 4.0 & 140 & 178.0 & 134.0 & 62.1 & 249.8 \\
\hline 4.0 & 160 & 186.0 & 138.0 & 66.1 & 257.8 \\
\hline 4.5 & 100 & 177.2 & 139.2 & 58.4 & 258.1 \\
\hline 4.5 & 120 & 185.2 & 143.2 & 62.4 & 266.1 \\
\hline 4.5 & 140 & 193.2 & 147.2 & 66.4 & 274.1 \\
\hline 4.5 & 160 & 201.2 & 151.2 & 70.4 & 282.1 \\
\hline 5.0 & 100 & 192.5 & 152.5 & 62.6 & 282.3 \\
\hline 5.0 & 120 & 200.5 & 156.5 & 66.6 & 290.3 \\
\hline 5.0 & 140 & 208.5 & 160.5 & 70.6 & 298.3 \\
\hline 5.0 & 160 & 216.5 & 164.5 & 74.6 & 306.3 \\
\hline
\end{tabular}

transported by hydraulic transport to make the mines viable.

(4) In opencast mines, production is greatly affected by haul road conditions, especially in monsoon months and hydraulic transport will prevent flooding of mines also.

(5) Most of the quality complaints and bill deductions can be minimized, if coal is crushed and it will be compulsory in case of hydraulic transport. 
(6) Haulage, winding and transport accidents in mines are next roof or side falls in occurrence and so from safety point of view also hydraulic transport is more suitable.

(7) Acid mine-water corrodes the pipelines and increase the cost of pipelines. The pipelines should be axially rotated while changing extraction district of and coal water slurry pumped for long life. Flexible and Composite pipes can be used and lot of research is going on.

(8) Delivery of coal slurry pipeline will be made at the top of a bunker from which water will be diverted to surface drainage and through a chute coal will be transported by trucks or conveyors.

(9) To overcome the issue of radio signal reliability, some remote-controlled pump-sets employs an internet-based modem working on the mobile phone network to communicate. Such system can ensure now that immediately on detection of pipe leakage pumps stop ensuring safety.

Acknowledgements The authors are thankful to Dr.Rajiv Shekhar, Director IIT(ISM), Dr. Shali Bahan, Dean (R\&D), and Dr. V.S.N.R Murthy, HOD(ME), IIT(ISM). Gratitude is expressed to Dr.D.C.Panigrahi, former Director IIT(ISM), former CMD, ECL, numerous faculties, at IIT, KGP \& IIT(ISM), Prof.Dr.M.A.Jawed, CIMFR, IIEST, Shibpur, who have helped indirectly in many ways.

Open Access This article is distributed under the terms of the Creative Commons Attribution 4.0 International License (http://crea tivecommons.org/licenses/by/4.0/), which permits unrestricted use, distribution, and reproduction in any medium, provided you give appropriate credit to the original author(s) and the source, provide a link to the Creative Commons license, and indicate if changes were made.

\section{References}

Duncan GJ (1998) Hydraulic coal mining developments in New Zealand. In: Coal operators conference. University of
Wollongong \& the Australasian Institute of Mining and Metallurgy, Australia, pp 333-342

Evans R, Roe P (2003) Water use and sustainable development in coal mining - a case study. In: Minerals network seminar II, Brisbane, Queensland, Australia, 17-18 Nov

https://www.royalihc.com/Home/Blog

https://encyclopedia2.thefreedictionary.com/Hydraulic+Transport

https://www.sciencedirect.com/topics/engineering/hydraulictransportation

https://link.springer.com/article/10.1007\%2Fs11771-008-0120-x

https://www.researchgate.net/publication/226418716_Hydraulic_calcu lation_of_gravity_transportation_pipeline_system_for_backfill_ slurry

https://www.sciencedirect.com/science/article/pii/S0032591002000311

https://www.researchgate.net/publication/251GV9Jm2u7rmsCe65wKz PTw5jtS38n2tVEGi_and_Analysis

https://www.fwi.co.uk/machinery/wilts-contractor-doubles-outputwith-remote-control-slurrypump

https://www.mining-technology.com/contractors/pumps/

Kumar S (2003) Global coal vision - 2030 19th world mining congress 'mining in the 21st Century - Quo Vadis?' 1-5th Nov, Oxford \& IBH Publishing Co. Pvt. Ltd., New Delhi

Kumar N, Sarkar S, Paul B (2013) Review on dewatering pumping network for underground coal mine In: 1st international \& 16th national conference on machines and mechanisms, IIT Roorkee, India, 18-20 Dec

Sakamoto M (1966) Hydraulic transportation of coal by hydro-hoists. J Mines Met Fuels- Min Tech \& Equip- Kolkata

Samaddar AB, Samanta BK (2002) Formulation of coal mining projects by expert system. J Mines Met Fuels 50(6):202-210

Samanta BK (1995) Environmental management of subsidence of mining areas with dredged sand from dams In: First world congress on mine environment. Oxford IBH, New Delhi, Dec

Samanta BK (1996a) Break-even point monitoring of collieries with database programming. Minetech 17(5):34-37

Samanta BK (1996b) Coal face mechanization selection and scheduling with a computer program in FORTRAN. Minetech 16(1\&2):34-43

Samanta BK, Sarkar BN (1993) Mine mechanization with machine safety and system safety In: XIII world congress on occupational safety and health, New Delhi

Wilson KC, Addie GR, Sellgren A, Clift R (2016) Slurry transport using centrifugal pumps. Springer

Yannopoulos S, Spiliotis M (2013) Water distribution system reliability based on minimum cut set approach and the hydraulic availability. Water Resour Manag 27:1821-1836. https://doi.org/ 10.1007/s11269-012-0163-5 